\title{
A IMIGRAÇÃO ALEMÃ NO LITORAL NORTE/RS: DISCURSOS SOBRE ETNICIDADE E MEMÓRIA
}

\author{
Sandra Cristina Donner*
}

\begin{abstract}
Resumo
Os discursos sobre a Imigração Alemã são múltiplos, podem vir dos historiadores acadêmicos, dos historiadores locais, dos centros de cultura. Este artigo é parte de uma reflexão maior, um projeto de doutoramento em História que pretende analisar os discursos dos historiadores amadores, não graduados, tendo como recorte o Litoral Norte/RS. O processo de Imigração Alemã nessa região também foi objeto das reflexões e pesquisas desses historiadores. A partir dos artigos presentes nos livros publicados pelos eventos de História Local, iremos apresentar as principais justificativas para a revitalização da memória da Imigração nessa região, bem como as questões de etnicidade presentes e a forma como estas são apresentadas ao público leitor. Por fim, a partir de Paul Ricoeur e François Hartog, iremos discutir os processos de memória e patrimonialização envolvendo a Imigração Alemã que estão em andamento nas últimas duas décadas no Litoral Norte/RS.
\end{abstract}

Palavras-chave: Imigração. Historiografia. História Local.

*Doutoranda em História na Universidade Federal do Rio Grande do Sul (UFRGS) e-mail: scdonner@yahoo.com 


\section{Introdução}

No presente artigo, pretendemos apresentar e discutir os discursos sobre imigração alemã no Litoral Norte/RS que circulam em dois grupos: os historiadores acadêmicos e os historiadores locais. A partir da apresentação destes não pretendemos fechar a questão apontando a validade do primeiro sobre o segundo, mas sim indicar que existem diferentes narrativas sobre o passado da região, cada uma delas circulando em um determinado grupo de "ouvintes". Enquanto os historiadores locais ancoram-se na memória como sua principal fonte, os historiadores acadêmicos tâm descoberto esse espaço como campo de investigação e diálogo entre outros projetos de imigração.

No Litoral Norte, as questões relativas à germanidade ou à origem étnica não são evidentes, embora tenham existidos núcleos de imigração em Torres e no distrito de Três Forquilhas. Durante muito tempo os estudos sobre História da Imigração focaram-se, principalmente, na região do Vale dos Sinos, Vale do Taquari e Paranhana. Recentemente, o Litoral Norte tem sido "descoberto" pelos historiadores e uma parcela da visibilidade que alcançou foi graças aos movimentos de História Local.

O conjunto de publicações que analisaremos são os Simpósios sobre Imigração Alemã no Litoral Norte - Marcas do Tempo, que iniciaram sob a inspiração do encontro Raízes - Encontro dos Municípios Originários de Santo Antônio da Patrulha. Dez anos separam o início dos dois eventos, que iniciaram em 1999, no município de Terra de Areia, e tiveram cinco edições, sendo a última em Dom Pedro de Alcântara, no ano de 2010. Foram publicados cinco livros, os quais também são fruto da coleta das comunicações e palestras ministradas durante as atividades. Ao todo foram publicados cinco livros, todos tendo como foco a imigração alemã no Litoral Norte e em alusão a alguma data comemorativa da imigração, como os aniversários de emancipação dos municípios envolvidos.

Os historiadores que participaram desses eventos, em sua maioria, também participavam dos encontros Raízes. A programação, em geral, constava de solenidade de abertura, com a fala do prefeito e dos secretários municipais envolvidos, conferência de abertura, palestras e comunicações. $\mathrm{O}$ evento era aberto à população e por isso ocorria em algum centro social da cidade (clubes e sociedades). Em vários textos encontramos 
a menção de que as escolas eram recrutadas para participarem, com os professores trazendo os alunos para acompanharem as palestras e tendo professores e estudantes como comunicadores ao longo do evento. Tal qual no Raízes, ocorriam momentos de lazer, com apresentações folclóricas alemãs, lançamentos de livros, apresentações musicais. Os momentos do intervalo eram espaço para interação entre os intelectuais, com participação da comunidade que colaborava com o coquetel com receitas da região.

Os livros, embora mais modestos do que os do Raízes, contam com 200 a 300 páginas, também publicados pela EST Editora. Entre os autores permanece a divisão entre historiadores vinculados a universidade, nomeados quanto aos seus títulos e procedência, historiadores chamados de "locais", com a determinação do município que é sua especialidade, "pesquisadores", com a sua profissão indicada e outros, dos quais apenas consta a profissão, sem nenhuma informação adicional. A partir do mapeamento dos autores, percebemos que esses "outros" apareciam apenas uma vez, sendo comunicadores eventuais no evento.

Os objetivos desses Simpósios sempre estão relatados nas primeiras páginas dos livros, são:

- Desenvolver a pesquisa sobre a formação étnica do Litoral Norte/ RS a partir da Colônia Alemã de Torres.

- Estimular o estudo dos hábitos e costumes dos imigrantes alemães, bem como, da língua alemã como forma de expressão cultural.

- Incentivar a inquirição genealógica das famílias que formam o universo populacional do Litoral Norte/RS.

- Intensificar a busca da consciência sociocultural da população do Litoral Norte/RS e sua contribuição no contexto do Estado.

- Perseverar na análise do entendimento comportamental dos descendentes dos imigrantes alemães no Litoral Norte/RS.

- Preservar a memória e registrar o cotidiano das comunidades teuto-brasileiras em nível regional.

- Resgatar a identidade histórica e os valores culturais dos habitantes da Colônia Alemã das Torres. (ELY, 2010, p. 14).

Como no caso do Raízes, a busca pela identidade por meio da história elou memória é destacada. No entanto, nesse caso, há um elemento a mais, uma busca por uma identidade étnica, que estaria sendo esquecida, soterrada tanto pelo mundo moderno como pela miscigenação que ocorreu na região, diferente de 

encontros, como foi apresentado acima, propõe a ativação étnica, a retomada de uma identidade perdida e, a partir dela, não apenas a valorização local, mas também uma chamada para que esses descendentes assumam suas "raízes".

Ao observarmos os artigos presentes nas obras Marcas do Tempo, especialmente os escritos por amadores ou memorialistas, podemos perceber que, as inferências sobre o passado provêm de relatos orais, pesquisas sem citação de fontes, com uma aproximação maior com a Memória do que com a História, tomando esta como um processo cercado de teoria e método.

Os livros de história municipal são elaborados, na maioria das vezes, para serem consumidos dentro das comunidades. Seus autores costumam ser pessoas da própria região, historiadores ou não que se propõem a "resgatar" e a contar a história de uma determinada localidade. E ao elaborar essas informações, estamos, também, elaborando memórias:

Quais são, portanto, os elementos constitutivos da memória, individual ou coletiva? Em primeiro lugar, são os acontecimentos vividos pessoalmente. Em segundo lugar, são os acontecimentos que eu chamaria de 'vividos por tabela', ou seja, acontecimentos vividos pelo grupo ou pela coletividade à qual a pessoa se sente pertencer. São acontecimentos dos quais a pessoa nem sempre participou, mas que, no imaginário, tomaram tamanho relevo que, no fim das contas, é quase impossível que ela consiga saber se participou ou não. (POLLAK, 1992, p. 201).

Essa memória forjada dentro dos grupos sociais é entendida por Michel Pollak (1992) como promotora de um sentimento de identidade, este, visto superficialmente, como a construção de sua própria representação, de como a pessoa vê a si mesma e de como pretende ser vista pelo grupo. Para a construção de identidade, três elementos seriam fundamentais: a unidade física, a continuidade no tempo e o sentimento de coerência.

A importância da memória como constituinte de identidade reside nas referências que a comunidade toma sobre o seu local e sobre sua posição frente ao outro. Justamente por esse caráter negociável é que a construção das memórias coletivas deve ser sempre questionada pela História. Isso nos leva a discussão sobre o papel do historiador e sua representação na sociedade. Segundo Ricoeur (2007, p. 274): 
[...] Uma coisa é um romance, mesmo realista; outra coisa, um livro de história. Distinguem-se pela natureza do pacto implícito ocorrido entre o escritor e seu leitor. Embora formulado, este pacto estrutura expectativas diferentes, por parte do leitor e promessas diferentes por parte do autor. [...] Ao abrir um livro de história, o leitor espera entrar, sob a conduta de um devorador de arquivos, num mundo de acontecimentos que ocorreram realmente.

Esse compromisso, no entanto, não está necessariamente presente nos eventos de História Local. Essas festas de família ou dos aniversários de fundação da cidade trazem a narrativa dos parentes mais antigos ou dos primeiros moradores. Um dos fatores de coesão da germanidade, assim como da italianidade, é a existência dessa narrativa dos pioneiros. Sua função recontando sua trajetória é unir os teutos das diversas colônias nesse passado comum. A proposta dos Simpósios era, então, por meio da retomada dessas narrativas, reavivar o sentimento de pertença étnica na região ou de etnogênese.

\section{Germanidade no Litoral Norte e os discursos sobre a História}

As relações das comunidades com o seu passado, ou melhor, com a "escolha" de seu passado e sua memória coletiva levam a fenômenos de reavivamento étnico. E esse processo de busca de passado e de identidade, étnica ou não, está ligado ao mundo contemporâneo. Segundo Nora (1993, p. 7):

A curiosidade pelos lugares onde a memória se cristaliza e se refugia está ligada a este momento particular da nossa história. Momento de articulação, onde a consciência da ruptura com o passado se confunde com o sentimento de uma memória esfacelada, mas onde o esfacelamento desperta ainda memória suficiente para que se possa colocar o problema de sua encarnação. O sentimento de continuidade torna-se residual aos locais. Há locais de memória porque não há mais meios de memória.

Com o conceito de etenogênese busca-se compreender esse processo de valorização da etnia que tem ocorrido no Rio Grande do Sul. Em diversos municípios a etnia é reativada pelos projetos de turismo, é o caso das cidades integrantes da "Rota Romântica". No objeto deste estudo, nos municípios do Litoral Norte, em 
especial o caso de Terra de Areia, isso ocorreu com os simpósios de imigração alemã no Litoral Norte. Sendo assim:

O termo etnogênese tem sido usado para designar diferentes processos sociais protagonizados pelos grupos étnicos. De modo geral, a antropologia recorreu ao conceito para descrever o desenvolvimento, ao longo da história, das coletividades humanas que nomeamos grupos étnicos, na medida em que se percebem e são percebidas como formações distintas de outros agrupamentos por possuírem um patrimônio linguístico, social ou cultural que consideram ou é considerado exclusivo, ou seja, o conceito foi cunhado para dar conta do processo histórico de configuração de coletividades étnicas como resultado de migrações, invasões, conquistas, fissões ou fusões. (BARTOLOMÉ, 2006, p. 39).

Esse movimento de retomada do passado e valorização de uma etnicidade ocorre, muitas vezes, em lugares onde a presença étnica não estava oculta, e sim ausente dos discursos acadêmicos ou políticos. A busca dessa identidade ocorre quando a obrigatoriedade de renúncia étnica deixa de existir pelo Estado ou por outro grupo social dominante, quando ocorre o fim do estigma sobre a filiação nativa ou também quando, por força de legislação ou por vantagens econômicas diversas (como no turismo), sua etnicidade pode trazer benefícios.

Embora alguns dos elementos citados a cima tenham uma aplicação material na vida dessas comunidades, o principal motor discursivo da etenogênese é o fortalecimento das relações comunitárias e a nova dignidade atribuída à sua história e à sua filiação. Ele encontra-se no processo de construção de sentido pelos diversos grupos sociais:

Mas também envolve uma capacidade de simbolização compartilhada, por meio da qual antigos símbolos se ressignificam e adquirem o papel de emblemas, capazes de serem assumidos como tais por uma coletividade que encontra neles a possibilidade de construir novos sentidos para a existência individual e coletiva. Se esses símbolos produzem efeitos dinamizadores, se encontram uma caixa social de ressonância, é porque têm certo nível de presença em alguns dos portadores da memória coletiva local e que os legitimam ante seus círculos mais próximos. (BARTOLOMÉ, 2006, p. 49).

Os agentes que mobilizam a comunidade nessa produção de etnicidade variam de caso a caso, muitas vezes são anciãos, 
intelectuais orgânicos ou memorialistas que retomam essa memória "esquecida" e a reatualizam em rituais e práticas cotidianas. Os livros de história municipal, escritos por "historiadores" locais, são uma dessas fontes. Além disso, relatos, histórias de vida e até mesmo artigos e pesquisas acadêmicas podem contribuir para esse processo.

Esses livros, segundo Bartolomé (2006), nem sempre correspondem a uma "verdade" historiográfica, uma vez que o mais importante é a reconstrução da narrativa étnica que pode dar um novo sentido a vida social daquele grupo. Para isso, muitas vezes, os textos consultados e resignificados são obras de antropólogos ou historiadores, produzidos para serem consumidos na academia e que acabam formando as bases de uma "ideologia étnica".

Nos encontros de História Local, principalmente nos Simpósio Marcas do Tempo, encontramos as questões que Bartolomé levantou. Nessas comunidades, os encontros pretenderam uma retomada da memória da imigração, chamada pelos autores de História. Os eventos eram promovidos por um grupo de colaboradores, entre historiadores locais e historiadores acadêmicos, que contaram com o apoio das prefeituras:

Ao apresentarmos Terra de Areia-Marcas do Tempo, I Simpósio sobre Imigração Alemã no Litoral Norte/RS e Raízes de Terra de Areia II, devemos registrar que esta obra só se tornou real graças à visão da administração pública municipal de Terra de Areia, na pessoa de seu prefeito Dr. Generi Máximo Lippert que, com perseverança e através da cultura, persegue um futuro promissor para sua comunidade. (ELY, 2000, p. 11).

Como foi exemplificado no relato acima, as administrações municipais realizam um uso político dessa história por meio da imagem dos imigrantes, pioneiros, que ocuparam a região. A necessidade de memória, alicerçada nos primeiros colonizadores, nesse caso, constitui-se em uma verdade forjada, já que havia um núcleo populacional já estabelecido nesses povoados antes da chegada dos alemães.

Em entrevista com alguns participantes dos eventos, foi mencionado que esses prefeitos, ao terem o seu nome vinculado com a história municipal, utilizavam o fato como promoção pessoal, todavia isso não ocorria de forma "maquiavélica". Os usos do passado são encontrados na medida em que seus nomes são perpetuados nos livros, quando ocorre a publicação. Além 
disso, os eventos buscavam agregar todos os cidadãos. Tanto que as escolas traziam os alunos, e os professores eram incentivados a realizarem pesquisas em conjunto com suas turmas a fim de coletar essa memória local, especialmente a vinculada às práticas culturais dos descendentes de imigrantes alemães.

A retomada das epopeias de imigração por meio dos eventos públicos não é um fenômeno exclusivo do Rio Grande do Sul ou do Brasil. Encontramos reflexões sobre isso na descrição dos usos da história francesa e podemos traçar paralelos:

A esse respeito, pode-se dizer que existem na França verdadeiras 'políticas públicas de memória', isto é, formas de gestão públicas do passado que tentam levar em conta essa necessidade de história e de contribuir, às vezes de maneira muito voluntarista, para a formação de um imaginário do passado. Essas políticas manifestam-se sob várias formas. (ROUSSO, 1997, p. 10).

Os espaços de manifestação dessa memória retomada/ recolocadas pelos órgãos públicos são as comemorações e as políticas de patrimonialização. As comemorações com motivos históricos pretendem unir os moradores por meio da partilha dessa memória coletiva. Ao reviver as narrativas dos antigos moradores, eles sentem-se incluídos no grupo, reforçam os laços de pertencimento. Para o poder público, é interessante estar ligado à promoção dessa memória. $\mathrm{O}$ passado é visto, então, dentro de um presente constante, é um passado para ser consumido:

Isso significa que vivemos em sociedades que parecem, de um lado ter perdido o ‘sentido’ da história, em sua acepção tradicional, entendido como um movimento contínuo e linear do progresso. Vivemos, assim, no presente, até mesmo na instantaneidade. Mas, por um lado, as referencias ao passado, à história, são cada vez mais frequentes no discurso comum, tanto quanto no político. A demanda social da história nunca esteve tão forte, a memória - ou seja, a presença do passado - nunca foi parte tão integrante da atualidade cotidiana: é particularmente claro na França, com tudo o que diz respeito às lembranças da última guerra. (ROUSSO, 1997, p. 16).

Nessas obras editadas a partir dos eventos de História Local, as definições entre história e memória são mais fluidas do que no universo acadêmico. Para essas administrações municipais, o grande objetivo, expresso de forma clara nos prefácios e capítulos de abertura, é tornar-se memória, apropriando-se do aval da história: 
Vivemos naqueles momentos inesquecíveis pela qualidade dos palestrantes que aqui se apresentaram com temas envolventes, despertando nosso interesse pela história da nossa região. [...] Aos que vieram comunicar ou ouvir relatos de famílias, resgatando as raízes e valorizando seus antepassados. Resta-me afirmar que sem dúvida foi um dos acontecimentos marcantes que jamais sairá de nossa memória; devendo servir de modelo às administrações que vem nos sucedendo. Sabemos que as crianças daquela época, alunos que participaram empolgados com pesquisas, danças e momentos culturais, hoje são cidadãos atuantes e influentes na política social do município podendo com suas ações mudar os rumos, baseados na educação e experiência que vivenciaram. Deli dos Reis Medeiros, secretária de educação de Terra de Areia durante o I Simpósio. (ELY, 2010, p. 35).

Outro objetivo que aparece como sendo um dos motivadores dos encontros é a divulgação dessa história "esquecida". $\mathrm{Na}$ primeira citação, a intensão de cativar as crianças e reativar a etnicidade está bem clara. Ao pesquisarem e assistirem as comunicações e palestras, essa memória seria passada adiante. Tal proposta conseguiu angariar fundos junto à iniciativa privada, unindo esforços com a organizadora e a equipe da prefeitura.

Nas produções que são objeto deste artigo, podemos perceber que o deslocamento populacional e, sobretudo, geracional, impõe a necessidade de "salvamento" de uma memória, nomeada como História pelas prefeituras e historiadores amadores. As histórias da pequena cidade, as tradições germânicas, os costumes locais, entre outros, estariam sendo perdidas no "mundo moderno", segundo esses intelectuais locais. Essa sensação colaborou para o sucesso dos eventos e apoio das prefeituras, como podemos ver em alguns prefácios escritos por autoridades municipais.

Tem-se nessas obras uma revisão e recordação dos hábitos e costumes quase esquecidos dos imigrantes; um apelo a que as pessoas atentem para a preservação de documentos, de objetos, de histórias ou estórias que se, não registradas, perder-se-ão; uma observação o quanto a fé acompanhou os imigrantes e que seria o 'norte' a ser seguido no árduo dia a dia, buscando, por meio da educação, o caminho seguro de seus descendentes. Com essa demanda pela memória, os discursos dos historiadores acadêmicos e dos historiadores memorialistas acabam entrando em conflito. O que cada um compreende como Memória e História acaba diferindo em termos conceituais e práticos. 


\section{Considerações finais}

Este pequeno artigo pretendeu apresentar um objeto de pesquisa ainda pouco explorado no campo historiográfico brasileiro. As obras de História Local, seus autores e sua apreensão pela população permanecem fora do foco das análises acadêmicas e com isso um vasto campo de produções deixa de ser compreendido e analisado, seja para ser aceito como produção histórica ou historiográfica ou seja para ser compreendido como um "uso da História”.

Essas obras apresentam uma pluralidade de abordagens sobre o passado. Lado a lado encontramos relatos memorialísticos e análises historiográficas, produzidas tanto por profissionais como por amadores. Cabe, então, compreender esses discursos sobre o passado como um exemplo da diversidade de autores e de públicos que se apropriam dessas narrativas, cada um com seus objetivos. Para os moradores, os livros de história local tornaram-se um espaço para contarem sua experiência, suas memórias, sua história. Para os historiadores acadêmicos que participaram desses eventos, foi proporcionado um espaço de divulgação científica, onde puderam levar suas pesquisas para o grande público, mas também onde partilharam suas memórias sobre as tradições da imigração.

De modo geral, percebemos que o espaço dado pelo poder público para a produção e publicação de história/memória se alargou a partir dos anos 90 . Os fatores podem ser os descritos por Nora (1993), a sensação de perda de identidade e memória que a atualidade nos traz, mas também podemos refletir sobre os usos públicos da História pelas administrações locais, onde a chancela das obras levaria adiante o seu nome ligado à promoção da cultura municipal. Os diversos discursos sobre o passado dos municípios, especialmente quanto às questões de etnicidade, ainda estão por serem mais bem compreendidos. $\mathrm{O}$ espaço dos atores sociais e sua conexão com o público-alvo pode nos levar às discussões sobre a História Pública e a apropriação dessas narrativas para fins comerciais, como o turismo, entre outros.

\section{Referências}

BARTOLOMÉ, Miguel Alberto. As Etnogênses: velhos atores e novos papéis no cenário cultural e político. Mana. Rio de Janeiro: UFRJ, vol. 12 (1): 39-68, 2006. 
ELY, Nilza Huyer (Org.). I Simpósio sobre Imigração Alemã no

Litoral Norte/RS - Terra de Areia Marcas do Tempo. Porto Alegre: Est Editora, 2000.

II Simpósio sobre Imigração Alemã no Litoral Norte/RS - Torres Marcas do Tempo. Porto Alegre: EST Editora, 2003.

III Simpósio sobre Imigração Alemã no Litoral Norte

- Três Cachoeiras Marcas do Tempo. Porto Alegre: EST Editora, 2004.

IV Simpósio sobre Imigração Alemã no Litoral Norte - Arroio do Sal Marcas do Tempo. Porto Alegre: EST Editora, 2006.

V Simpósio sobre Imigração Alemã no Litoral Norte - Dom Pedro de Alcântara - Marcas do Tempo. Porto Alegre: EST Editora, 2010.

HALBSWACHS. Maurice. Memória Coletiva. São Paulo: Vértice, 1971.

NORA, Pierre. Entre Memória e História, a problemática dos lugares. In: Projeto História. São Paulo: PUC, 1993.

POLLAK, Michel. Memória e Identidade Social. In: Estudos Históricos. Rio de Janeiro: FGV, vol. 5, no 10, 1992.

Memória, Esquecimento, Silêncio. In: Estudos

Históricos, Rio de Janeiro: FGV, vol. 2, nº 3, 1989.

POMIAN, Krzystof. Sobre la História. Madrid: Cátedra, 2007.

POUTIGNAT, Philippe, STREIFF-FERNART, Jocelyne. Teorias da Etnicidade. São Paulo: UNESP, 1998.

RICOEUR, Paul. A Memória, a História, o Esquecimento. Campinas: Unicamp, 2007.

ROUSSO, Henry. Usos do passado na França de hoje. In: SIMSON, Olga Rodrigues de Moraes (Org.). Os desafios contemporâneos da História Oral. Campinas: Ed. UNICAMP, 1997.

As identidades dos imigrantes e o melting pot nacional. In: Horizontes Antropológicos. Porto Alegre: UFRGS, v. 6, n. 14 , nov. 2000, p. 143-176.

Etnicidade política e ascensão social: Um exemplo

teuto-brasileiro. In: Mana. Rio de Janeiro: UFRJ, n. 5, 1999, p. 61-88. 


\title{
THE DISCOURSE ON GERMAN IMMIGRATION IN THE NORTH COAST/ RS: A REFLECTION ON ETHNICITY AND MEMORY
}

\begin{abstract}
The discourse on German immigration are multiple, can come from academic historians, local historians, the cultural centers. This article is part of a larger reflection, a $\mathrm{PhD}$ project in History you want to analyze the speeches of amateur historians, not graduates, with the cut the North Coast / RS. The German immigration process in this region was also the subject of reflection and research of these historians. From the present articles in books published by the Local History events, we will present the main reasons for the revitalization of the Immigration memory in this region as well as the questions of ethnicity present and how they are presented to the reading public. Finally, from Paul Ricoeur, and François Hartog will discuss memory processes and patrimonialization involving the German immigration that are in progress in the last two decades in the North Coast / RS.
\end{abstract}

Keywords: Immigration. Historiography. Local History. 